\title{
Fabricato: 100 años de legado social
}

Leidy Diana Uribe Betancur y Jorge Andrés Suárez Quirós*

\section{Introducción}

El presente capítulo describe los frentes de acción social más institucionalizados por parte de Fabricato desde sus inicios hasta la actualidad. Si bien la empresa efectuaba acciones reiteradas y puntuales en materia de beneficencia, como donaciones y auxilios económicos a personas y entidades públicas y privadas, el texto presenta las acciones más sistemáticas y de mayor impacto que al principio estuvieron dirigidas a los empleados administrativos y a los obreros dedicados a la producción textil, y que luego trascendieron las fronteras de la empresa, al incluir a sus familias y a los habitantes del municipio de Bello; incluso, algunas de estas acciones tuvieron alcances departamental y nacional.

En este sentido, se destacan la consolidación de la política de vivienda obrera, los aportes a la educación, el Secretariado Social y la creación de la Clínica Fabricato; de igual manera, la conformación de la brigada de bomberos, el servicio de la proveeduría, el apoyo al cooperativismo a través de la Cooperativa de Trabajadores de Fabricato, Cotrafa, y la Cooperativa de Empleados de Pantex, Coopantex. También se destaca la creación de la Corporación Fabricato para el Desarrollo Social, punto de inflexión cuando la compañía transformó su accionar social para dar paso a lo que hoy se conoce como responsabilidad social empresarial. 